\title{
The Concept, Diagnostics, Surgical Prevention and Treatment of Hereditary Colorectal Cancer in Nowadays Medicine
}

\author{
Andrejs Vanags, Ilze Strumfa, Arnis Abolins, Andris Gardovskis, \\ Inga Melbarde-Gorkusa, Genadijs Trofimovics, Janis Gardovskis \\ Hereditary Cancer Institute, Riga Stradins University, Riga, Latvia
}

\begin{abstract}
Summary
Colorectal cancer is a frequent cause of oncological morbidity and mortality. It is the second most common cancer in Europe $(13.0 \%)$ almost matching the frequency of lung cancer, the most widespread malignancy (13.2\%). In European Union countries colorectal cancer is the most frequent tumour. Colorectal cancer is also the second most common cause of cancer death in Europe accounting for $11.9 \%$ of cancer-related mortality (4). In $20 \%$ of colorectal cancer patients, genetic background exists. However, the discovered genetic mutations related to high lifetime risk of colorectal cancer account only for 5-6\% of colorectal cancer cases (27). The two main hereditary cancer syndromes involving the large bowel are familial adenomatous polyposis, responsible for $1 \%$ of the annual colorectal cancer burden, and hereditary non-polyposis colorectal cancer that accounts for 2-3\% of colorectal cancer cases (9). Both syndromes are remarkable not only by the scientific novelty in hereditary cancer research but only for high practical significance as the knowledge about the peculiar risk of primary and metachronous colorectal cancer as well as about certain extracolonic malignancies is necessary to plan the surgical intervention correctly.
\end{abstract}

Key words: colorectal cancer, familial adenomatous polyposis, hereditary non-polyposis colorectal cancer.

\section{Hereditary non-polyposis colorectal cancer}

Hereditary non-polyposis colorectal cancer (HNPCC) is caused by germline mutation in any of the DNA mismatch repair genes (MMR) and is characterised by early-onset colorectal cancer, mostly in proximal location; an increased risk of metachronous colorectal tumours and a characteristic, wide spectrum of benign and malignant extracolonic tumours (9). This syndrome comprises $2-3 \%$ of colorectal cancers (13).

The history of HNPCC concept began in 1966 when Lynch et al. described the family aggregation of colorectal, gastric and endometrial cancers under the term "cancer family syndrome". Later the syndrome was designated Lynch syndrome or HNPCC (27). The diagnostic criteria of HNPCC are following. Set of criteria called Amsterdam Criteria I request the presence of all the subsequent facts: 1) at least three relatives affected by histologically verified colorectal cancer and one of the patients is a first-degree relative of the other two. Familial adenomatous polyposis must be excluded; 2) colorectal cancer involving 2 or more generations; 3 ) at least one colorectal cancer case diagnosed before the age of 50 . The other set of criteria, known as Amsterdam Criteria II, allows using the presence of certain extracolonic cancers for the diagnosis of HNPCC syndrome: 1) at least three relatives with histologically verified HNPCCassociated cancer, one of whom is a first-degree relative of the other two. Familial adenomatous polyposis must be excluded; 2) colorectal cancer diagnosed in 2 or more generations; 3 ) at least one HNPCC-related cancer diagnosed before the age of 50. The HNPCC-related tumours in the diagnostic context include endometrial cancer, cancer of the small intestine and of renal pelvis or ureter (27). However, awareness exists that not all HNPCC cases can be diagnosed by these criteria (9).

The published frequency of HNPCC varies widely, from $1 \%$ to $13 \%$ of colorectal cancers (27). The cause of HNPCC is a mutation in mismatch repair genes with autosomal dominant mode of inheritance. The MMR genes include MSH2 (human mutS homologue 2) and MSH6 (human muts homologue 6), both on chromosome 2pl6; MLH1 (human mutL homologue 1) on chromosome 3p21; PMS1 (human post meiotic segregation 1) on chromosome 2q31 and PMS2 (human post meiotic segregation 2) on chromosome $7 \mathrm{ql}$ l. Germline mutations of $M S H 2$ and $M L H 1$ account for more than $95 \%$ of mutations in HNPCC families (27). MMR mutations are detected in $60 \%$ of Amsterdam criteria fulfilling families (17).

The lifetime risk of colorectal cancer in HNPCC-related mutation carriers is $80 \%$, and the average age of diagnosis is 44 years (18). HNPCC-related colorectal cancer is characterised by more frequent occurrence in the right side of colon (18), certain histological features (Figure 1), high rate of microsatellite instability, improved survival but high risk of metachronous colorectal cancer. The rate of right colonic tumours is $60-80 \%$ in HNPCC vs. $23-32 \%$ of sporadic colorectal cancers (18). Histologically, HNPCC-related colorectal cancers are characterised by high grade, mucinous component and more marked host response (27). The risk of metachronous colorectal cancer in 10 years after surgical resection is $45 \%(27)$. 
HNPCC is associated with elevated risk of extracolonic tumours, including endometrial, gastric, small intestinal, pancreatic, biliary tree, ovarian cancer, transitional cell carcinoma and brain tumours $(13,30)$. The cumulative risk of extracolonic tumour is $47.4 \%(95 \% \mathrm{CI}=43.9$ $50.85)$ for females and $26.5 \%(95 \% \mathrm{CI}=22.6-30.4 \%)$ for males at the age of 70 years, considering proven and obligate mutation carriers and their first degree-relatives (2). Males have significantly higher risks of gastric (2) and urologic (31) cancer. Gastric cancer has lifetime risk of $5.8 \%$ to the age of 70 years with the greatest risk within interval 50-65 years and low risk before the age of 50 years (31). Other groups have reported higher lifetime risk - 12\% in Korea (20), 13\% in Finland (1) and even $18 \%$ (11). The risk of endometrial cancer is as high as $39 \%$ by the age of 70 (27). Slightly higher risk estimate of $43 \%$ is also described (11). The risk of ovarian cancer is $6.7-9 \%$ by the age of $70(27,31)$. It is higher in $\mathrm{MSH} 2$ mutation carriers. The highest risk period for ovarian cancer is from age 40 to 55 years, but $8 / 72$ of ovarian cancers were diagnosed even before the age of 35 years (31). The lifetime risk of urologic cancer is $8.4 \%(95 \%$ CI $=6.6-10.8)$. The risk of urothelial cancer in HNPCC is 1.6 times higher in males than in females and 7 times higher in $M S H 2$ than in $M L H 1$ family members (31). Breast cancer occurs in HNPCC families at the same risk as in general population (31). The lifetime risk of brain tumours is estimated to be $2 \%$; these neoplasms frequently occur in young patients and have dismal prognosis. Twenty-six percent of brain tumours develop before 25 years of age, the lethality is $90 \%$; and almost one forth of death cases occurs before the age of 25 years (31). The relative risk of small intestinal cancer as well as cancer of the biliary tree is increased in comparison to general population (27).

Analysing cancers developing in mismatch repair gene mutation carriers, the frequency of high-level microsatellite instability is different according to the location: high $(96-100 \%)$ in ureteric, gastric and colorectal cancer, intermediate $(60-63 \%)$ in endometrial cancers and cancer of urinary bladder, low (0-25\%) in renal cancer and brain tumours (10) suggesting different pathways of carcinogenesis.

The management of HNPCC include screening and eligible treatment, optimized for the presence of mutation and the associated risk. No childhood measures are necessary in contrast to FAP (27). The screening includes search for colorectal and endometrial cancer in combinations with screening for other malignancies if indicated by family cancer history (9). First-degree relatives of affected individuals should undergo colonoscopy every $1-2$ years starting between 20 and 30 years and annually after 40 years of age. For mutation carriers it is advised to start annual colonoscopies at the age of 25 or 5 years before the age of diagnosis of the youngest case in the family, whichever comes first (27). Annual screening for endometrial cancer should be started at age 25-35 and include endometrial aspiration or transvaginal ultrasound (27). Endometrial cancer is the only extracolonic tumour location for which there is evidence of surveillance benefit as diagnostics of tumours in early stage can be achieved (13). Preventive measures for ovarian cancer should be used beginning at the age of 40. Early oophorectomy could be considered, probably in MSH2 mutation carriers (31). Prophylactic gynaecologic surgery is suggested to be the best preventive option in females who have completed childbearing plans (19). Surveillance has been recommended for urinary tract and gastric cancer if these tumours are present in the kindred (13). Alternatively, surveillance for urothelial cancer is recommended for carriers of $\mathrm{MSH} 2$ mutations after age of 50. Ultrasonography and urine cytology can be used to screen for urinary tract cancer (9). Regular gastric surveillance is suggested by some (8) but rejected by other scientists (31). It seems reasonable to recommend annual oesophagogastroduodenoscopy for those patients whose pedigrees are marked by presence of gastric cancer cases (9).

Prophylactic total colectomy with ileorectal anastomosis can be considered in MMR mutation carriers for whom endoscopic surveillance is not possible or who refuse to undergo it $(9,22)$. Performing colorectal cancer surgery, risk of synchronous and metachronous cancer must be taken into account (27). If cancer is present, partial colectomy carries higher cancer risk than total colectomy with ileorectal anastomosis (9); the risk can be as high as $12 \%$ in $10-12$ years $(9,16)$. If the first tumour is a rectal cancer, total proctocolectomy can also be considered as the risk of proximal metachronous cancer is $17-45 \%(9,16,28)$. Prophylactic hysterectomy and bilateral salpingoovarectomy should be considered after completing childbirth, especially during colorectal surgery. There is no evidence of the efficacy of chemoprotection (13).

\section{Familial adenomatous polyposis (FAP)}

FAP is an autosomal dominant disorder caused by germline mutation in the tumour suppressor $A P C$ gene on chromosome 5q12. The principal manifestation of this syndrome is the development of numerous (at least 100) colorectal adenomas beginning from teenage years. At the age of 35 years, 95\% of FAP patients have developed adenomas (27). Due to malignization in accordance with the adenoma-carcinoma sequence, the lifetime risk of colorectal cancer approaches $100 \%$ with the average age of cancer diagnosis at 34.5-43 years (27). A wide spectrum of benign extracolonic manifestations is possible as well as extracolonic malignancies including hepatoblastoma, small intestinal, biliary and pancreatic tumours, thyroid malignancies and brain tumours. Attenuated FAP (25) is characterised by lower number of adenomas (20-100) and later cancer development (7).

FAP can be caused by any of more than 300 mutations described in APC (15). These mutations include insertions, deletions and nonsense mutations resulting in frameshift or premature stop codons that, in turn, truncate the APC protein. Approximately 10\% of FAP patients share one mutation - the deletion of AAAAG in codon 1309 (27). Genotype-phenotype correlations are confounded by the significant variability. 

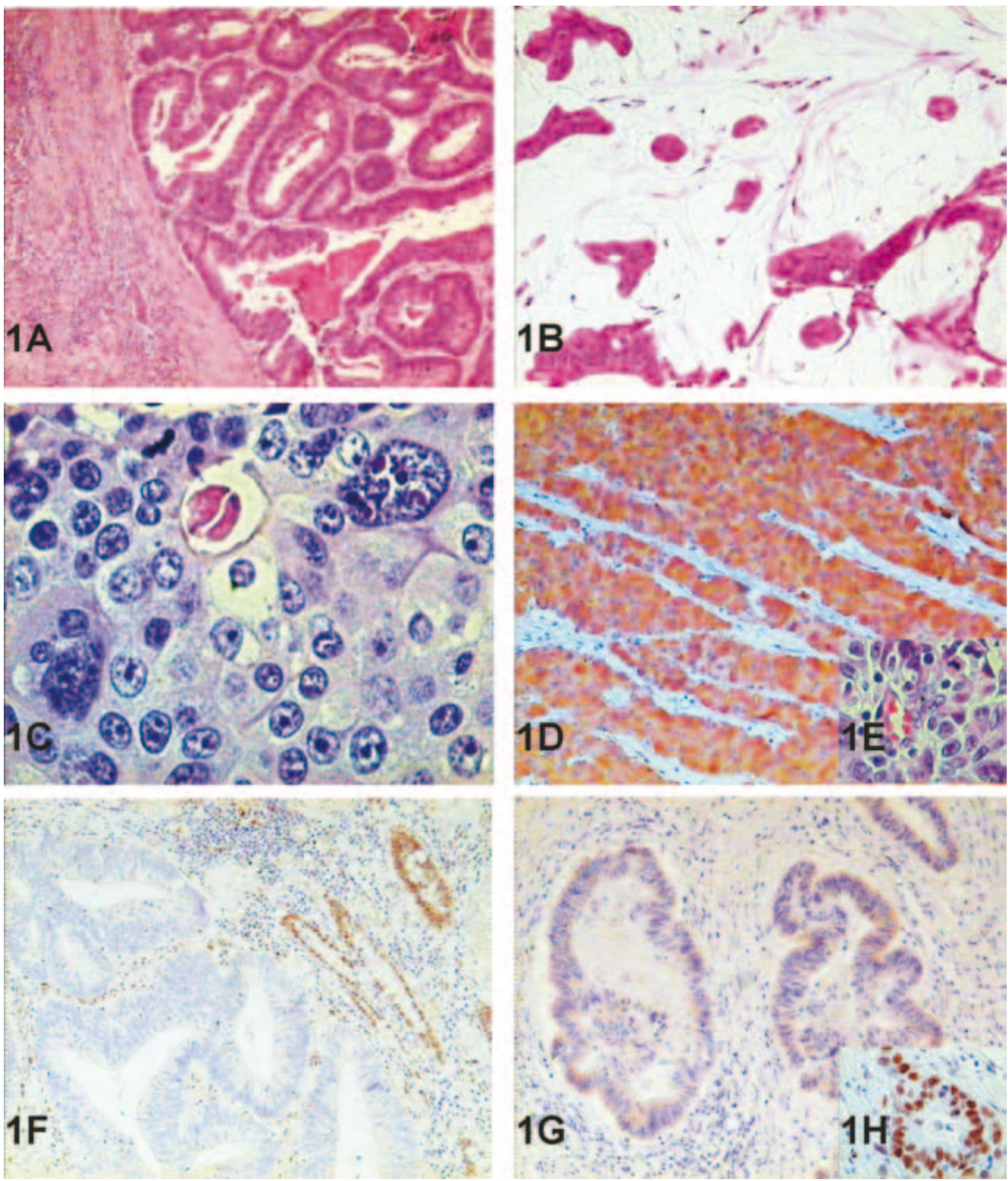

Fig. 1. Morphological traits of hereditary non-polyposis colorectal cancer. 1A, border showing trend to expanding growth, haematoxylin-eosin (HE), original magnification (OM) X100; 1B, mucinous component, HE, OM x100; 1C, high cancer grade, HE, OM x400; undifferentiated solid pattern, cytokeratin AE1/AE3, immunoperoxidase (IP), OM x100; 1E (inset), more marked host response in the form of high number of intratumoural lymphocytes within solid cancer, HE, OM X400; 1F, lack of MSH2 protein in hereditary colorectal cancer cells in contrast to benign cells, IP, MSH2 protein, OM X100; 1G, lack of MSH6 protein in hereditary colorectal cancer cells, IP, MSH6 protein, OM X100; 1H (inset), positive control for MSH6 protein visualisation: expression of MSH6 protein in sporadic colorectal cancer, IP, MSH6 protein, OM X400 
An unusual variant of $A P C$ mutation has been described in $6 \%$ of Ashkenazi Jews. A missense mutation Il307K implies twofold lifetime risk of colorectal cancer. The replacement of thymine by adenine in the surrounding adenine-rich sequence results in long adenine chain. During DNA replication, this site becomes prone to somatic mutations $(14,27)$.

The management of FAP patients include timely diagnostics, prophylaxis of colorectal cancer and follow-up by optimal schedule in order to detect some less frequent ominous manifestations. It has been suggested to diagnose FAP as early as at the age of 10-12 years (27), optimally by genetic testing of first-degree relatives of FAP patients, alternatively by yearly sigmoidoscopy (colonoscopy if attenuated FAP is suggested) decreasing the frequency of endoscopy with each decade if negative. Full colonoscopy is suggested after the diagnosis has been established. The timing of surgery depends on the severity of the initial manifestations. Severe polyposis, severe dysplasia, tubulovillous architecture, multiple adenomas larger than $5 \mathrm{~mm}$ and such symptoms as bleeding, diarrhoea, anaemia and failure to thrive are indications to consider early surgical treatment $(6,9)$. In cases with small adenomas and strong family history of abdominal desmoid disease the colectomy could be delayed (9). The surgical approaches include total proctocolectomy with permanent ileostomy, total colectomy with ileorectal anastomosis and proctocolectomy with ileal pouch - anal anastomosis. Total proctocolectomy with permanent ileostomy is indicated for patients with poor sphincter function or tumour invasion in sphincter as well as in case of mesenteric desmoid. The colectomy is associated with high rectal cancer risk of $4-8 \%$ in 10 years and $26-32 \%$ in 25 years $(3,29)$. It is not recommended for patients having severe rectal polyposis with more than 20 adenomas, marked colonic polyposis with more than 1000 adenomas, adenoma larger then $3 \mathrm{~cm}$ or an adenoma with severe dysplasia $(5,6,9)$. Endoscopic surveillance is recommended at 6-12 month intervals after the surgery. The functional outcome after total colectomy with ileorectal anastomosis and proctocolectomy with ileal pouch - anal anastomosis has been matter of discussions (9).

Hepatoblastoma is a childhood tumour that is curable by early surgery but may cause death if not treated properly. As the risk of hepatoblastoma is $1: 150$ in $A P C$ mutation carriers and 1:300 in their children, screening with serum alpha-fetoprotein levels and liver imaging is advised in children of FAP patients from infancy to 5 years of age (27).

Prophylactic use of COX-2 inhibitors is under research. Non-steroidal anti-inflammatory drugs sulindac, rofecoxib, celecoxib, exisulid reduce the polyp number and size in FAP patients but rectal cancer can develop even on background of seemingly successive polyp control (9). The compliance and adverse effects also remain questionable issues. It is recommended to consider these medications in particular situations like refusal from colectomy or necessity to reduce polyp number in order to facilitate endoscopic control of them and to postpone the scarring to such a degree that cancels any efforts of polyp fulguration or polypectomy (9).

Even if hepatoblastoma has been avoided or treated in the childhood and colorectal cancer risk is controlled, death of FAP patient can be caused by desmoids or cancer in the duodenal area. Desmoids occur in 12$17 \%$ of FAP patients $(6,24)$. These tumours frequently are intraabdominal and occur after abdominal surgery suggesting they are triggered by surgical intervention $(9,24)$. Surgical treatment may be difficult. Tamoxifen can be used if the tumour is slowly growing or mildly symptomatic, vinblastine and methotrexate can be used in more aggressive cases but doxorubicin and dacarbazine can be used for rapidly growing tumour (9). The rate of duodenal adenomas in FAP patients is $80-90 \%$ with a risk of malignancy $3-5 \%$. The surveillance includes upper gastrointestinal endoscopy beginning from the age of 25-30 years. Endoscopic removal, pancreas-preserving duodenectomy or pancreaticoduodenectomy are among the treatment options. It seems that COX-2 inhibitors are even less effective in order to control duodenal polyposis (9).

\section{other hereditary/familial colorectal cancer syndromes}

Hereditary colorectal cancer can be caused by mutations other than APC or MMR genes. CRAC gene is mapped to 15q14-22 (26). MYH gene mutations bring an increased colorectal cancer risk in a recessive mode, presenting mostly as attenuated polyposis (21). Testing for $M Y H$ gene mutations is advised in patients with at least 15 colorectal adenomas and family history suggesting recessive mode of inheritance (23). Clinically, familial colorectal cancer can be diagnosed as the aggregation of 3 cancer cases in the same location among blood relatives is considered a high risk cluster (12); however, if the pedigree corresponds to the diagnostic criteria of HNPCC, this more specific diagnosis should be used.

\section{CONCLUSIONS}

1. The two main hereditary colorectal cancer syndromes involving the large bowel represent familial adenomatous polyposis and hereditary non-polyposis colorectal cancer.

2. The diagnostics of hereditary colorectal cancer syndromes should involve the evaluation of family history, endoscopic, morphological and molecular findings.

3. Once hereditary colorectal cancer syndrome is diagnosed, attention should be paid to surveillance and timely surgical prophylaxis of colorectal cancer and extracolonic malignancies.

4. If the hereditary colorectal cancer syndrome patient is diagnosed with colorectal cancer, risk of metachronous cancer must be considered deciding the extent of operation.

Conflict of interest: None 


\section{REFERENCES}

1. Aarnio M, Sankila R, Pukkala E, Salovaara R, Aaltonen LA, de la Chapelle A, Peltomäki P, Mecklin JP, Järvinen HJ. Cancer risk in mutation carriers of DNA-mismatch-repair genes // Int J Cancer, 1999; 81:214-218

2. Barrow E, Robinson L, Alduaij W, Shenton A, Clancy T, Lalloo F, Hill J, Evans DG. Cumulative lifetime incidence of extracolonic cancers in Lynch syndrome: a report of 121 families with proven mutations // Clin Genet, 2009; 75(2):141 - 149

3. Bertario L, Russo A, Radice P, Varesco L, Eboli M, Spinelli P, Reyna A, Sala P. Genotype and phenotype factors as determinants for rectal stump cancer in patients with familial adenomatous polyposis. Hereditary Colorectal Tumors Registry // Ann Surg, 2000; 231:538 - 543

4. Boyle P and Ferlay J. Cancer incidence and mortality in Europe, 2004 // Ann Oncol, 2005; 16: 481 - 488

5. Church J, Burke C, MsGannon E, Pastean O, Clark B. Predicting polyposis severity by proctoscopy: how reliable is it? // Dis Colon Rectum, 2001; $44: 1249-1254$

6. Church J, Simmang C. Practice parameters for the treatment of patients with dominantly inherited colorectal cancer (familial adenomatous polyposis and hereditary nonpolyposis colorectal cancer) // Dis Colon Rectum, 2003; 46:1001 - 1012

7. Giardiello FM, Brensinger JD, Luce MC, Petersen GM, Cayouette MC, Krush AJ, Bacon JA, Booker SV, Bufill JA, Hamilton SR. Phenotypic expression in adenomatous polyposis families with mutation in the $5^{\prime}$ region of the adenomatous polyposis coli gene // Ann Intern Med 1997; 126:514 - 519

8. Goecke T, Schulmann K, Engel C, HolinskiFeder E, Pagenstecher C, Schackert HK, Kloor M, Kuntsmann E, Vogelsang H, Keller G, Dietmaier W, Mangold E et al. Genotype - phenotype comparison of German MLH1 and MSH2 mutation carriers clinically affected with Lynch syndrome: A report by the German HNPCC Consortium // J Clin Oncol, 2006; $24: 1-8$

9. Guillem JG, Wood WC, Moley JF, Berchuck A, Karlan BY, Mutch DG, Gagel RF, Weitzel J, Morrow M, Weber BL, Giardiello F, Rodriguez-Bigas MA, Church J, Gruber S, Offit K. ASCO/SSO review of current role of risk-reducing surgery in common hereditary cancer syndromes // Ann Surg Oncol, 2006; 13:1296- 1321

10. Gylling AH, Nieminen TT, Abdel-Rahman WM, Nuorva K, Juhola M, Joensuu EI, Järvinen HJ, Mecklin JP, Aarnio M, Peltomäki PT. Differential cancer predisposition in Lynch syndrome: insights from molecular analysis of brain and urinary tract tumors // Carcinogenesis, 2008; 29(7):1351 - 1359

11. Hampel H, Frankel WL, Martin E, Arnold M, Khanduja K, Kuebler P, Nakagawa H, Sotamaa K, Prior TW, Westman J, Panescu J, Fix D, Lockman J, Comeras I, de la Chapelle A. Screening for the Lynch syndrome (hereditary nonpolyposis colorectal cancer) // N Engl J Med, 2005; 352: $1851-1860$

12. Hampel H, Sweet K, Westman JA, Offit K, Eng C. Referral for cancer genetics consultation: a review and compilation of risk assessment criteria // J Med Genet, 2004; 41:81 - 91

13. Koornstra JJ, Mourits MJ, Sijmons RH, Leliveld AM, Hollema H, Kleibeuker JH. Management of extracolonic tumours in patients with Lynch syndrome // Lancet Oncol, 2009; 10(4):400 40Laken SJ, Petersen GM, Gruber SB, Oddoux C, Ostrer H, Giardiello FM, Hamilton SR, Hampel H, Markowitz A, Klimstra D, Jhanwar S, Winawer S, Offit K, Luce MC, Kinzler KW, Vogelstein B. Familial colorectal cancer in Askenazim due to a hypermutable tract in APC // Nature Genet, 1997; $17: 79-83$

14. Laurent-Puig P, Beroud C, Soussi T. APC gene: database of germline and somatic mutations in human tumors and cell lines // Nucl Acids Res, $1998 ; 26: 269-270$

15. Lee JS, Petrelli NJ, Rodrigues-Bigas MA. Rectal cancerin hereditary nonpolyposis colorectal cancer// Am J Surg, 2001; 181:207 - 210

16. Lynch HT, de la Chapelle A. Hereditary colorectal cancer. N Engl J Med, 2003; 348(10):919 - 932

17. Lynch HT, Shaw MW, Magnuson CW, Larsen AL, Krush AJ. Hereditary factors in two large midwestern kindreds // Arch Intern Med, 1996; 117:206 - 212

18. Manchada R, Menon U, Michaelson-Cohen R, Beller U, Jacobs I. Hereditary non-polyposis colorectal cancer or Lynch syndrome: the gynaecological perspective // Curr Opin Obstet Gynecol, 2009; $21(1): 31-38$

19. Park YJ, Shin KH, Park JG. Risk of gastric cancer in hereditary nonpolyposis colorectal cancer in Korea // Clin Cancer Res, 2000; 6:2994 - 2998

20. Sampson JR, Dolwani S, Jones S, Eccles D, Ellis A, Evans DG, Frayling I, Jordan S, Maher ER, Mak T, Maynard J, Pigatto F, Shaw J, Cheadle JP. Autosomal recessive colorectal adenomatous polyposis due to inherited mutations of $\mathrm{MYH} / /$ Lancet, 2003; 362:39-41

21. Scaife CL, Rodriguez-Bigas MA. Lynch syndrome: implications for the surgeon // Clin Colorectal Cancer, 2003; 3:92 - 98

22. Sieber OM, Lipton L, Crabtree M, Heinimann K, Fidalgo P, Philipps RK, Bisgaard ML, Orntoft TF, Aaltonen LA, Hodgson SV, Thomas HJ, Tomlinson IP. Multiple colorectal adenomas, classic adenomatous polyposis, and germ-line mutations in $\mathrm{MYH} / / \mathrm{N}$ Engl J Med, 2003; 348(9):791 - 799

23. Soravia C, Berk T, McLeod RS, Cohen Z. Desmoid disease in patients with familial adenomatous polyposis // Dis Colon Rectum, 2000; 43:363 - 369

24. Spirio L, Olscwang S, Groden J, Robertson M, Samowitz W, Joslyn G, Gelbert L, Thliveris A, Carlson M, Otterud B et al. Alleles of the APC gene: an attenuated form of familial polyposis // Cell, 1993; 75:951 - 957 
25. Tomlinson I, Rahman N, Frayling I, Mangion J, Barfoot R, Hamoudi R, Seal S, Northover J, Thomas HJ, Neale K, Hodgson S, Talbot I, Houlston R, Stratton MR. Inherited susceptibility to colorectal adenomas and carcinomas. Evidence for a new predisposition gene on 15q14-q22 // Gastroenterology, 1999; 1 16:789 - 795

26. Trimbath JD, Giardiello FM. Review article: genetic testing and counselling for hereditary colorectal cancer // Aliment Pharmacol Ther, 2002; 16: $1843-1857$

27. Vasen HF, Nagengast FM, Khan PM. Interval cancers in hereditary non-polyposis colorectal cancer (Lynch syndrome) // Lancet, 1995; 345:1183-1184

28. Vasen HF, van der Luijt RB, Slors JF, Buskens E, de Ruiter P, Baeten CG, Schouten WR, Oostvogel HJ, Kuijpers JH, Tops CM, Meera Khan P. Molecular genetic tests as a guide to surgical management of familial adenomatous polyposis // Lancet, 1996; 348:433- 435

29. Watson P, Lynch HT. Extracolonic cancer in hereditary nonpolyposis colorectal cancer // Cancer, 1993; 71:677-685

30. Watson $\mathrm{P}$, Vasen HF, Mecklin JP, Bernstein I, Aarnio M, Järvinen HJ, Myrhøj T, Sunde L, Wijnen JT, Lynch HT. The risk of extra-colonic, extraendometrial cancer in the Lynch syndrome // Int J Cancer, 2008; 123(2): $444-449$

\section{Acknowledgement}

AV is supported by ESF fellowship, project

Nr. 2009/0147/1DP/1.1.2.1.2/09/IPIA/VIAA/009.

\section{Address:}

Andrejs Vanags,

Hereditary Cancer Institute,

Riga Stradins University,

Dzirciema Street 16, LV-1007, Riga, Latvia,

phone: +37167069974, fax: +37167069973,

e-mail: vanags314@inbox.lv 